\title{
0 rádio em sintonia: do MEB à WEB
}

\section{Viviam Lacerda de Souza}

\section{Resenha}

PRETTO, Nelson De Luca; TOSTA, Sandra Pereira (Org.). Do MEB à WEB: 0 rádio na educação. Belo Horizonte: Autêntica, 2010. 208 p.
Viviam Lacerda de Souza I viviamlacerd@gmail.com Publicitária. Doutoranda em Comunicação Social pela Universidade Metodista de São Paulo (UMESP).
A obra Do MEB à WEB: o rádio na educação possibilita ao leitor uma reflexão acerca da proposta da rádio educativa na era digital, trafegando pelo universo do Movimento da Educação de Base (MEB) em um histórico do passado, suas articulações com o futuro e as possibilidades das tecnologias digitais nas rádios web e nas práticas comunitárias no exercício da cidadania.

Deste modo, o rádio, capaz de difundir a informação com interatividade, amplia conhecimentos por meio da linguagem. Como dimensão de aprendizagem, ensina, e através de tecnologias da era digital cria mudanças no paradigma educacional do país. Podemos dizer que $D o$ MEB à $W E B$ aborda desde métodos tradicionais da educação até formas inovadoras de educar com democracia no exercício da cidadania, despertando o interesse do educando, possibilitando maior compreensão e assimilação de conteúdo pedagógicos. Trata-se de métodos atuais de ensinar e aprender com criatividade e interação, pluralizando vozes na prática de vivência da alteridade, pois no momento da difusão da informação se dá o direito do educando 
discutir e desenvolver o censo crítico acerca das mídias e a originalidade de seus conteúdos sejam eles reflexo ou não da indústria cultural.

Nos artigos apresentados no livro observamos discussões sobre temas variados como a atuação do MEB na área popular em termos de alfabetização, mobilização social e a utilização do rádio como mecanismo de educação e pedagogia na intensificação do estado de consciência do educando-ouvinte e na reconstrução de imagem perceptiva em um contexto de experiências, hábitos, estados afetivos, valores e visões de futuro. Observase que a utilização do rádio no processo educacional se caracteriza como a aplicação de um desenvolvimento tecnológico capaz de adentrar em realidades distintas possibilitando a difusão pedagógica, independente da distância física, o que demonstra 0 exercitamento dos direitos à cidadania e à informação.

Outra abordagem mostra que a educação, por meio da cultura do povo, se caracterizou como Movimento da Cultura Popular (MCP), uma tentativa para tirar da ignorância e alfabetizar as vítimas do monopólio político da região Nordeste, que conviveu paralelamente com o MEB e foi chamada de Universidade Popular. Há um contraponto do pensamento de Paulo Freire que reconhece problemas resultantes da união entre a mídia, a educação e a cultura popular como uma questão de comunicabilidade, o que gerou repercussões negativas. Outro aspecto apresentado ao leitor é 0 caráter democratizante do MCP em relação ao MEB, o que conduz ao raciocínio de um progresso nacional atrelado a oferta de trabalho para a população e a defesa pela indústria da pátria. Assim, o homem consciente é aquele dono de seu próprio destino, 0 que só se torna possível a partir do voto e da escolha pelos seus representantes na administração pública e 0 MPC, por meio da alfabetização e da valorização da cultura, possibilita à sociedade a esperança do crescimento do Brasil.

0 rádio se apresenta na obra também sob 0 aspecto da acessibilidade no país e sua relevância na democratização da comunicação e legislação das rádios comunitárias no Brasil. Neste caso, uma pesquisa realizada pela Faculdade de Educação da Universidade Federal da Bahia (FACED/UFBA) sobre o rádio e seu princípio da oralidade, que objetiva a implantação estratégica do projeto de uma rádio web para 0 desenvolvimento da comunidade acadêmica, se depara com 0 desafio da construção de propostas acerca da linguagem radiofônica diante do significado educacional e da deficiência de uma rede de banda larga no país, principalmente para as classes sociais mais carentes. Desse modo, questões de acessibilidade do rádio em termos quantitativos no país e sua relevância permeiam o tema Democratização da Comunicação e legislação das rádios comunitárias no Brasil, tanto em termos de apropriação política, partidária e eleitoreira dos meios, quanto de convergência midiática. Percebe-se que as relações entre rádio, educação e Tecnologia da Informação e Comunicação (TICs) demonstram a possibilidade 
de um mais comunicacional dentro de uma sala de aula interativa. A proposta observada é a de um novo olhar sobre o potencial das TICs como uma forma abrangente de educar, comunicar e interagir, possibilitando a Pedagogia da Assimilação, ou seja, da transformação do Outro no Eu, uma nova forma de ensinar e aprender. Assim, a acessibilidade e a hipertextualidade do rádio web permitem ao usuário mais autonomia e liberdade de escolha, motivando-o a uma aprendizagem significativa e com possibilidade de produção de novos conhecimentos, de forma mais significativa e com possibilidade de produção de novos conhecimentos, de forma mais participativa e coerente.

Dessa forma, abre-se espaço para discussões acerca das rádios livres e comunitárias que são diferenciadas em termos conceituais, históricos e legais para a posterior exposição das características das rádios comunitárias, quando nem tudo o que se diz comunitário realmente 0 é. Nos processos de rádios comunitárias também se desenvolve a Educomunicação, o que demanda políticas públicas democráticas de comunicação. Essa demanda se expressa em manifestações comunicacionais que podem conduzir à cidadania e são tentativas ou desejos de exercitá-la. Neste sentido, as rádios comunitárias demonstram a motivação por questões coletivas, mobilizações e participações populares, pela democracia da informação no processo de educação informal, ou seja, pelo direito à cidadania. A obra elucida que nas comunidades, as rádios comunitárias buscam a vivência da alteridade na prática ao estabelecerem uma relação pacífica e construtiva com as diferenças, o que conduz à cidadania. Pesquisas mostram que os agrupamentos comunitários criam condições de sobrevivência, vínculos identitários e interações sociais para o estabelecimento de uma comunicação que contribui com a pluralização de vozes e práticas educativas transformadoras de esferas públicas locais.

A partir desse tema a obra traz a experiência da Radioforum, um espaço na internet onde radioartistas, produtores e teóricos do rádio criam narrativas sonoras possuidoras de vida própria que estimulam a discussão dos usuários sobre as produções, estabelecendo a democracia da informação e o direito à cidadania. A Radioforum surge a partir da insatisfação com 0 mundo de interesses comerciais que limita o rádio em seu papel educativo, cultural e artístico, o que compromete a experimentação e a criação nas ondas sonoras, pois este, como outros veículos, se apropria da linguagem dos meios de comunicação existentes, anulando ou inibindo suas características próprias. Também o Projeto Educom.radio, alicerçado basicamente na educação para os meios, se mostra como uma produção colaborativa de forma democrática entre educadores e educandos para ensinar e aprender simultaneamente por meio de negociação de sentidos e práticas midiáticas. Neste projeto, cada professor se transforma em um comunicador para uma formação conjunta e compartilhada do aluno, para que toda a comunidade exercite a comunicação aberta com a democracia. Trata-se de uma atribuição da educomunicação à revolução através do rádio, 
uma vez que este possibilita a diminuição do índice de violência nas escolas públicas e contribui para a transformação da prática de convivência dialógica permanente por meio da expressão de sujeitos sociais, na interface Comunicação/Educação.

A curiosa relação do médico Roquette-Pinto com 0 rádio e sua convicção de ser este um canal possuidor de poder, provocador de mudanças na mentalidade popular, fez com que articulasse dois campos do saber: comunicação e educomídia ou educomunicação. Neste cenário, outras experiências do rádio no campo da educação tornam evidente 0 Projeto de Extensão de Rádio Educativo da Universidade Federal de Minas Gerais (UFMG) como uma proposta geradora de conhecimento aos alunos por meio do rádio nas TICs de modo a provocar mudanças no paradigma educacional do país. Assim, os meninos do rádio, a que se refere 0 título do artigo, são os alunos das escolas estaduais contempladas pelo projeto Rádio Educativo da UFMG, rotulados como aprendizes de cidadania, motivo pelo qual se desenvolve a educação através dos saberes e fazeres do rádio.

Outras observações são feitas sob o Ciência na Favela, programa laboratório para experimentações de formatos e estratégias de divulgação da ciência pelo rádio para averiguar distanciamentos entre o rádio e a sala de aula, espaços de aprendizagem e diferenças na performance do educador na instância midiática ou escolar. Definia-se o livre arbítrio do saber por meio da sedução da descoberta, considerando 0 ato de ensinar, suprindo ou implantando o papel da escola, como também o fomento do ensino.

Por fim, a obra aborda a questão da evolução tecnológica do rádio e sua possibilidade de interaçãa plena por meio das tecnologias digitais no rádio na perspectiva educacional de intensificar os processos colaborativos e coletivos, no momento em que liberdade se constitui a palavra-chave. A discussão caminha para o futuro do veículo em termos de qualidade, possibilidades de leitura $\mathrm{e}$ eliminação de interferências sonoras a fim de que uma única emissora possa operar diferentes tipos de transmissões por meio de um software livre. Também a resistência do rádio e sua consolidação na era da cibercultura e da convergência, tal como seu potencial educacional e formador de comunidades de aprendizagem abrem espaço ao crescimento das experiências radiofônicas no uso pedagógico pelo mundo, como nas duas modalidades de rádio educativa (rádios universitárias do Minho, em Portugal, e da Universidade Nacional de Educação à Distância, na Espanha), as quais abrem espaço para 0 apontamento de alternativas e tendências. Como exemplificação disso, uma plataforma on-line, PUBLIRADIO.NET, de suporte a disciplinas de rádio que facilita a aprendizagem do alunado, permitindolhes a construção de produtos publicitários radiofônicos de forma ágil, interativa, e estimulante. 


\section{Expediente}

A revista E-Compós é a publicação científica em formato eletrônico da Associação Nacional dos Programas de Pós-Graduação em Comunicação (Compós). Lançada em 2004, tem como principal finalidade difundir a produção acadêmica de pesquisadores da área de Comunicação, inseridos em instituições do Brasil e do exterior.

\section{E-COMPÓS I www.e-compos.org.br I E-ISSN 1808-2599}

Revista da Associação Nacional dos Programas

de Pós-Graduação em Comunicacão.

Brasília, v.16, n.2, maio/ago. 2013

A identificação das edições, a partir de 2008

passa a ser volume anual com três números.

\section{CONSELHO EDITORIAL}

Afonso Albuquerque, Universidade Federal Fluminense, Brasil Alberto Carlos Augusto Klein, Universidade Estadual de Londrina, Brasil Alex Fernando Teixeira Primo, Universidade Federal do Rio Grande do Sul, Brasil Ana Carolina Damboriarena Escosteguy, Pontifícia Universidade Católica do Rio Grande do Sul, Brasi

Ana Gruszynski, Universidade Federal do Rio Grande do Sul, Brasil Ana Silvia Lopes Davi Médola, Universidade Estadual Paulista, Brasil André Luiz Martins Lemos, Universidade Federal da Bahia, Brasil Ângela Freire Prysthon, Universidade Federal de Pernambuco, Brasil Antônio Fausto Neto, Universidade do Vale do Rio dos Sinos, Brasil Antonio Carlos Hohlfeldt, Pontifícia Universidade Católica do Rio Grande do Sul, Brasil Antonio Roberto Chiachiri Filho, Faculdade Cásper Líbero, Brasil Arlindo Ribeiro Machado, Universidade de São Paulo, Brasil Arthur Autran Franco de Sá Neto, Universidade Federal de São Carlos, Brasil Benjamim Picado, Universidade Federal Fluminense, Brasil

César Geraldo Guimarães, Universidade Federal de Minas Gerais, Brasil Cristiane Freitas Gutfreind, Pontifícia Universidade Católica do Rio Grande do Sul, Brasil Denilson Lopes, Universidade Federal do Rio de Janeiro, Brasi Denize Correa Araujo, Universidade Tuiuti do Paraná, Brasil Edilson Cazeloto, Universidade Paulista , Brasi Eduardo Peñuela Cañizal, Universidade Paulista, Brasil Eduardo Vicente, Universidade de São Paulo, Brasil Eneus Trindade, Universidade de São Paulo, Brasi Erick Felinto de Oliveira, Universidade do Estado do Rio de Janeiro, Brasi Florence Dravet, Universidade Católica de Brasilia, Brasil Francisco Eduardo Menezes Martins, Universidade Tuiuti do Paraná, Brasil Gelson Santana, Universidade Anhembi/Morumbi, Brasil Gilson Vieira Monteiro, Universidade Federal do Amazonas, Brasil Gislene da Silva, Universidade Federal de Santa Catarina, Brasil Guillermo Orozco Gómez, Universidad de Guadalajara

Gustavo Daudt Fischer, Universidade do Vale do Rio dos Sinos, Brasil Hector Ospina, Universidad de Manizales, Colômbia

Herom Vargas, Universidade Municipal de São Caetano do Sul, Brasi leda Tucherman, Universidade Federal do Rio de Janeiro, Brasil Inês Vitorino, Universidade Federal do Ceará, Brasil Janice Caiafa, Universidade Federal do Rio de Janeiro, Brasil Jay David Bolter, Georgia Institute of Technology Jeder Silveira Janotti Junior, Universidade Federal de Pernambuco, Brasil João Freire Filho, Universidade Federal do Rio de Janeiro, Brasil John DH Downing, University of Texas at Austin, Estados Unidos
José Afonso da Silva Junior, Universidade Federal de Pernambuco, Brasi José Carlos Rodrigues, Pontifícia Universidade Católica do Rio de Janeiro, Brasi José Luiz Aidar Prado, Pontifícia Universidade Católica de São Paulo, Brasil José Luiz Warren Jardim Gomes Braga, Universidade do Vale do Rio dos Sinos, Brasil Juremir Machado da Silva, Pontifícia Universidade Católica do Rio Grande do Sul, Brasil Laan Mendes Barros, Universidade Metodista de São Paulo, Brasil Lance Strate, Fordham University, USA, Estados Unidos Lorraine Leu, University of Bristol, Grã-Bretanha Lucia Leão, Pontifícia Universidade Católica de São Paulo, Brasil Luciana Panke, Universidade Federal do Paraná, Brasil Luiz Claudio Martino, Universidade de Brasília, Brasil Malena Segura Contrera, Universidade Paulista, Brasil Márcio de Vasconcellos Serelle, Pontifícia Universidade Católica de Minas Gerais, Brasil Maria Aparecida Baccega, Universidade de São Paulo e Escola Superior de Propaganda e Marketing, Brasil

Maria das Graças Pinto Coelho, Universidade Federal do Rio Grande do Norte, Brasil Maria Immacolata Vassallo de Lopes, Universidade de São Paulo, Brasil Maria Luiza Martins de Mendonça, Universidade Federal de Goiás, Brasi Mauro de Souza Ventura, Universidade Estadual Paulista, Brasil

Mauro Pereira Porto, Tulane University, Estados Unidos Nilda Aparecida Jacks, Universidade Federal do Rio Grande do Sul, Brasi Paulo Roberto Gibaldi Vaz, Universidade Federal do Rio de Janeiro, Brasi Potiguara Mendes Silveira Jr, Universidade Federal de Juiz de Fora, Brasi Renato Cordeiro Gomes, Pontifícia Universidade Católica do Rio de Janeiro, Brasil Robert K Logan, University of Toronto, Canadá

Ronaldo George Helal, Universidade do Estado do Rio de Janeiro, Brasil Rosana de Lima Soares, Universidade de São Paulo, Brasi Rose Melo Rocha, Escola Superior de Propaganda e Marketing, Brasil Rossana Reguillo, Instituto de Estudos Superiores do Ocidente, Mexico Rousiley Celi Moreira Maia, Universidade Federal de Minas Gerais, Brasi Sebastião Carlos de Morais Squirra, Universidade Metodista de São Paulo, Brasil Sebastião Guilherme Albano da Costa, Universidade Federal do Rio Grande do Norte, Brasil

Simone Maria Andrade Pereira de Sá, Universidade Federal Fluminense, Brasi Tiago Quiroga Fausto Neto, Universidade de Brasília, Brasil Suzete Venturelli, Universidade de Brasília, Brasil Valério Cruz Brittos, Universidade do Vale do Rio dos Sinos, Brasil Valerio Fuenzalida Fernández, Puc-Chile, Chile

Veneza Mayora Ronsini, Universidade Federal de Santa Maria, Brasi Vera Regina Veiga França, Universidade Federal de Minas Gerais, Brasil

\section{COMISSÃO EDITORIAL}

Adriana Braga I Pontifícia Universidade Católica do Rio de Janeiro, Brasi

Felipe Costa Trotta I Universidade Federal Fluminense, Brasi CONSULTORES AD HOC

Alexandre Barbalho, Universidade Estadual do Ceará, Brasil

Ana Carolina Escosteguy, Pontifícia Universidade Católica do Rio Grande do Sul, Brasi

Ana Gruszynski, Universidade Federal do Rio Grande do Sul, Brasi

Arthur Ituassu, Pontifícia Universidade Católica do Rio de Janeiro, Brasil

Claudia Lahni, Universidade Federal de Juiz de Fora, Brasil

Francisco Paulo Jamil Marques, Universidade Federal do Ceará, Brasil

Jiani Bonin, Universidade do Vale do Rio dos Sinos, Brasil

José Luiz Braga, Universidade do Vale do Rio dos Sinos, Brasil

Leonel Aguiar, Pontifícia Universidade Católica do Rio de Janeiro, Brasil

Luciana Panke, Universidade Federal do Paraná, Brasil

Marcelo Kischinhevsky, Universidade do Estado do Rio de Janeiro, Brasil

Raquel Paiva, Universidade Federal do Rio de Janeiro, Brasil

Sandra Rubia da Silva, Universidade Federal de Santa Maria, Brasil

EDIČ̃̃ DE TEXTO E RESUMOS I Susane Barros

SECRETÁRIA EXECUTIVA I Juliana Depiné

EDITORAÇ̃̃o ELETRÔNICA I Roka Estúdio

TRADUÇÃO I Sieni Campos
COMPós I www.compos.org.br

Associação Nacional dos Programas de Pós-Graduação em Comunicação

Presidente

Eduardo Morettin

Universidade de São Paulo, Brasil

eduardomorettin@usp.br

Vice-presidente

Inês Vitorino

Universidade Federal do Ceará, Brasil

ines@ufc.br

Secretária-Geral

Gislene da Silva

Universidade Federal de Santa Catarina, Brasil

gislenedasilva@gmail.com 